\begin{tabular}{l} 
O P E R A T I O N S R E S E A R C H A N D D E C I S I O N S \\
\hline No. 4
\end{tabular}

DOI: $10.37190 /$ ord200403

\title{
FROM EXPECTED UTILITY THEORY TO PROSPECT THEORY. TRACKING DOWN THE EXPERIMENTAL PATH AFTER FORTY YEARS
}

\author{
SŁAWOMIR KALINOWSKI $^{*}$ \\ Department of Microeconomics, Poznań University of Economics and Business, \\ al. Niepodległości 10, 61-875 Poznań, Poland
}

\begin{abstract}
The expected utility theory axioms have been studied experimentally. Three of the experiments are a repetition of an earlier test in slightly changed circumstances, while the other two are original. The participants were incentivised with rewards, which did not happen in the replicated tests. The results confirmed the degeneration of the expected utility theory as a scientific research program. The evidence that resulted from the tests supported the hypothesis on the cumulative prospect theory predicting facts not forecasted by the EUT.
\end{abstract}

Key words: economic decisions under risk, expected utility theory, cumulative prospect theory, experimental economics

\section{Introduction}

The article aims to perform an experimental test of the EUT axioms once again. Vernon Smith's methodological concept on the role of experiments in the economic theory stresses a cautious attitude to the interpretation of results. When a theory works well, they push imaginatively to find deliberately destructive experiments that will uncover its edges of validity, setting the stage for better theory and a better understanding of the phenomena. When a theory works poorly, they re-examine instructions for lack of clarity, increase the experience level of subjects, try increased payoffs, and explore sources of "error" in an attempt to find the limits of the falsifying conditions; again, this is for the purpose of better understanding the anatomy of a theory's failure, or the procedures for testing it, and thereby laying the basis for improving the theory [31, p. 129].

*Email address: slawomir.kalinowski@ue.poznan.pl

Received 1 July 2020, accepted 3 December 2020 
The article begins with a brief presentation of the expected utility theory followed by experiments testing its axioms. Two of them are the repetition of original (man and Tversky's tests from the article on prospect theory [15]. One repeated Loomes, Starmer and Sudgen's test on transitivity axiom [18]. Another is a test on the Alllais paradox [3]. Yet another one tests reference point significance with Kahneman's set of lotteries [16]. The next section is devoted to a presentation of prospect theory in both original (PT) and cumulative version (CPT). The article closes with a summary designed as the test of the CPT predictive capacity.

\section{Expected utility theory}

In 1713, Nicolas Bernoulli described the St. Petersburg paradox that inspired him to develop the expected utility concept. In 1738, Daniel Bernoulli, Nicolas' cousin, published a paper describing the expected utility theorem [7]. The article introduced a concept of marginal utility and concave utility of wealth function. Two centuries later, in 1944, von Neumann and Morgenstern supplemented the expected utility theory (EUT) with an axiomatic framework [36]. They defined utility as a subjective value that individuals attribute to monetary outcomes. The expected utility is the sum of these values multiplied by the probabilities of their occurrence:

$$
E(v(m))=p_{1} v\left(m_{2}\right)+\ldots+p_{t} v\left(m_{t}\right) ; p_{1}+p_{2}+\ldots+p_{t}=1
$$

Rational decision-makers under the expected utility theory were defined according to von Neumann and Morgenstern by their preferences that meet four axioms ${ }^{1}$ :

- Completeness. For two different lotteries $M$ and $N$, one may state that $M$ is preferred over $N(M \succ N)$, or $N$ is preferred over $M(M \prec N)$, or the choice is indifferent $(M \approx N)$. The set of lotteries with undetermined preference is empty.

- Transitivity. If $M \succ N$, and $N \succ O$, then $M \succ O$.

- Independence. Let there be three lotteries $M, N$, and $O$. If $M \succ N$, then $p M+(1-p) O$ $\succ p N+(1-p) O, p \in[0 ; 1]$. Adding the same alternative to the lotteries does not change the preference.

- Continuity. If $M \succ N \succ O$, then there is always the probability $p \in[0 ; 1]$ that gives $p M+(1-p) O \approx N$. When there are three lotteries ordered from the most preferred to

${ }^{1}$ Originally VNM formulated six axioms, which were later reduced to the four presented in the article. 
the least preferred, there is always the probability that mixes the extreme ones, making this lottery equally preferred as the middle one.

Von Neumann and Morgenstern needed the EUT in the axiomatic framework to introduce mixed strategies into their game theory paradigm. Originally, the third axiom of independence was not formulated by VNM explicitly. Its later formulation opened the door for the EUT as a coherent concept explaining human choices under risk in normative as well as in positive sense. In 1954, Savage developed the EUT introducing personal probability [27]. When the probabilities of the events are not given, the attitude of the decision-makers to an alternative will depend on their assessment of the likelihoods of those events.

\section{Prospect theory}

The violations of the EUT axioms in real people's choices under risk undermined its positive capacity to explain them. It directly led Kahneman and Tversky to build a new theory that could predict human behaviour in risky situations. The core of the theory is the definition of the prospect that is divided into two components: (i) the riskless component, i.e., the minimum gain or loss which is certain to be obtained or paid; (ii) the risky component, i.e., the additional gain or loss which is actually at stake. The evaluation of such prospects is described in the following equation [15]. If $p+q=1$ and either $x>y>0$ or $x<y<0$, then

$$
V(x, p ; y, q)=v(y)+\pi(p)(v(x)-v(y))
$$

where: $x, y$-monetary outcomes, $p, q$-probabilities of the outcomes, $v(x), v(y)$-values of the outcomes, $\pi(p)$ - probability weighting function.

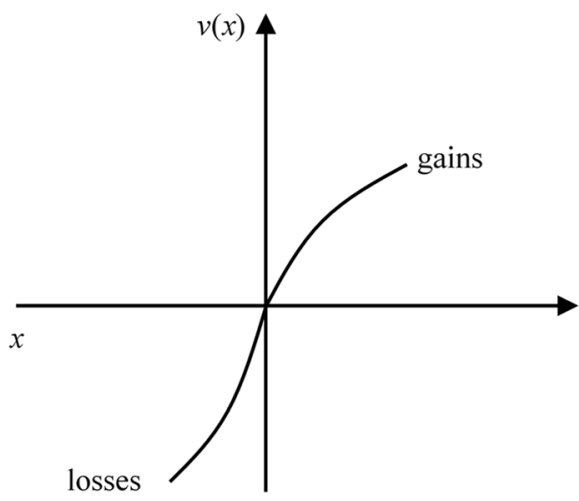

Fig. 1. Value function of the prospect [15] 
Kahneman and Tversky designed a value function concave for gains and convex for losses. The loss aversion phenomenon also imposed the value curve for losses that is steeper than for gains. The value curve in the first version of the prospect theory is presented in Fig. 1.

Thirteen years later, Kahneman and Tversky developed the prospect theory into the cumulative prospect theory (CPT). The CPT introduced the proposal of the particular value functions with the calibration of the parameters [33]. Its absence was the weakness of the original version of the theory, as Kahneman and Tversky themselves stated [15]. The value functions were defined separately for gains and losses

$$
v(x)= \begin{cases}x^{\alpha} & \text { if } x \geq 0 \\ -\lambda(-x)^{\beta} & \text { if } x<0\end{cases}
$$

The estimated parameters are: $\alpha=\beta=0.88$, and $\lambda=2.25$ which is the median measure for loss aversion.

The probability weighting function in the original version of the prospect theory is shown in Fig. 2. It captured all the empirical phenomena as far as people's reaction to risk is concerned. They treat $p$ very close to zero as zero, the same is for events which are almost sure. The subjects overestimate low probabilities and underestimate medium and high ones.

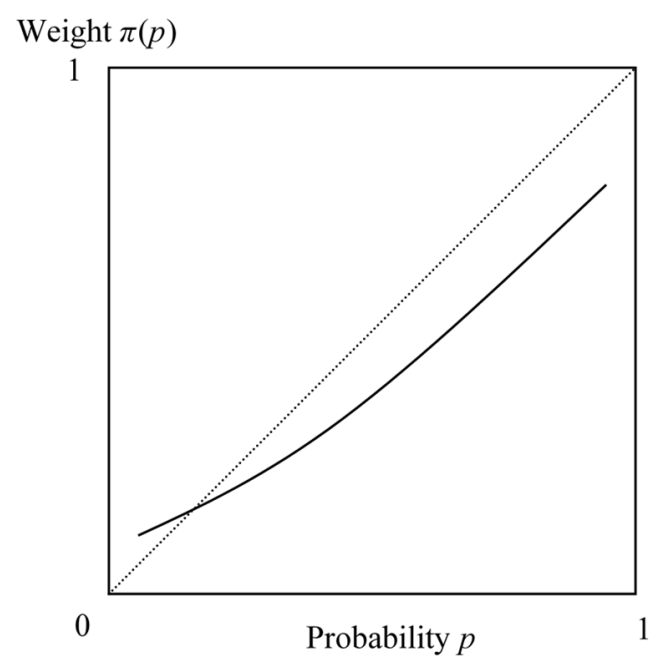

Fig. 2. Probability weighting function of the prospect [15]

Further development of the concept brought the proposal of the weighting functions and calibration of the parameters separately for gains and losses: 


$$
w^{+}(p)=\frac{p^{\gamma}}{\left(p^{\gamma}+(1-p)^{\gamma}\right)^{1 / \gamma}}, \quad w^{-}(p)=\frac{p^{\delta}}{\left(p^{\delta}+(1-p)^{\delta}\right)^{1 / \delta}}
$$

where the estimated values are $\gamma=0.61$, and $\delta=0.69$ [33]. A particularly important modification within the cumulative prospect theory is a different definition of $p$. It is no longer the probability of the outcome $x$. In the CPT $p$ is defined as the probability of winning not less than $x$. For the lowest gain of the lottery cumulated $p=1$.

\section{Experiments}

The empirical domain of the article is founded on the results of five experiments. The first one is a test of the famous Allais paradox [3]. The second one is a repetition of Loomes, Starmer and Sudgen's test on the transitivity axiom [18]. Experiments 3 and 4 are performed on the choices investigated by Kahneman and Tversky in their canonical article on the prospect theory [15]. The last experiment was designed on Kahneman's example, illustrating the significance of the reference point for people's choices under risk [16]. The set of experiments was selected to test the common violations of the EUT axioms.

The participants were doctoral students at Poznan University of Economics and Business. The tests were performed in the years 2015-2020 at the beginning of the Economic Decision Making course. The sample included 90 students, 51 males and $39 \mathrm{fe}-$ males, each participated in each of the five experiments. The students were taking choices without knowledge of the expected utility theory or prospect theory. After the completion of choices, the draws were performed. Afterwards, each participant was informed about their rewards. The participants were incentivised by the possibility of winning points to facilitate passing the course ${ }^{2}$. To standardise different units of rewards, they were recalculated as the share of the maximum available value in the experiment. Then, there was an average per cent value from the five experiments calculated for each participant and it was multiplied by 20 points. The minimal number of points to pass the course was 50. The average reward was 9.5 credit points from a maximum of 100 .

\footnotetext{
${ }^{2}$ The majority of studies testing alternative incentives in experiments proved that rewarding participants with extra-credit points brings essentially the same results as in case of monetary rewards, see $[11,12,20]$.
} 


\section{Experiment 1}

First doubts about the EUT were disseminated by Allais at the 1952 Paris conference on risk. He presented his famous example questioning the axioms founding the EUT, especially the axiom of independence. Allais used his paradox as the illustration to his alternative to the EUT concept on decision-making under risk [3].

Table 1. Allais paradox

\begin{tabular}{|c|c|c|c|c|c|c|c|c|c|c|c|c|c|c|c|}
\hline \multicolumn{7}{|c|}{ Choice 1.1} & \multicolumn{1}{c|}{ Choice 1.2} \\
\hline$p_{a 1}$ & 1 & $m_{a 1}$ & 100 & $p_{b 1}$ & 0.10 & $m_{b 1}$ & 500 & $p_{c 1}$ & 0.11 & $m_{c 1}$ & 100 & $p_{d 1}$ & 0.1 & $m_{d 1}$ & 500 \\
\hline & & & & $p_{b 2}$ & 0.89 & $m_{b 2}$ & 100 & $p_{c 2}$ & 0.89 & $m_{c 2}$ & 0 & $p_{d 2}$ & 0.9 & $m_{d 2}$ & 0 \\
\hline & & & & $p_{b 3}$ & 0.01 & $m_{b 3}$ & 0 & & & & & & & & \\
\hline
\end{tabular}

Source: [3].

The Allais paradox consists of two choices presented in Table 1. The EUT weights the utilities by their probabilities. Hence, subtracting the same expected utility from both lotteries does not change the preference:

$$
v(100)<0.1 v(500)+0.89 v(100) \text { then } 0.11 v(100)<0.1 v(500)
$$

According to Allais' intuition, the respondents would choose A over B, expected utility's independence axiom was incompatible with the preference for security in the neighbourhood of certainty [6]. So, the hypothetical preference is

$$
v(100)>0.1 v(500)+0.89 v(100)
$$

Subtraction of $0.89 v(100)$ from both sides gives

$$
0.11 v(100)>0.1 v(500)
$$

which violates either the EU prediction or another obvious intuition. The axiom of independence was exposed by subtracting options A and B by $m=100$ with the probability of 0.89 to obtain options $\mathrm{C}$, and D, respectively. According to the EU hypothesis, this operation should not reverse the preferences. For example, those who choose A should choose C.

Allais presented no empirical results supporting his paradox till 1979. In his article [4], he revealed the results of a questionnaire regarding the paradox, performed in 1952, that resulted in $46 \%$ choices violating the EU hypothesis. However, after fifteen years, a series of important experiments testing Allais paradox was initiated. The first one, performed 
by MacCrimon [21], was the most complex. He tested multiple variants of choices generated by a designed set of parameters. Another study by Moskovitz [25] tested a version that sustained probabilities and changed payoffs. The experiment performed by Slovic and Tversky [30] scrutinised Allais' exact set of choices. Kahneman and Tversky in their article launching prospect theory [15] exploited the results of an experiment ( $\mathrm{K} \& \mathrm{~T}$ experiment) on a set of choices with either probabilities or outcomes changed (compared to Allais' set the differences between values and probabilities were reduced). These experiments revealed from 27 to $61 \%$ of EU hypothesis violations understood by the AC pair. Table 2 describes the results obtained by Kahneman and Tversky [15].

Table 2. Kahneman and Tversky's experiment (1979) [15]

\begin{tabular}{|c|c|c|c|c|c|c|c|c|}
\hline Choices & \multicolumn{4}{|c|}{ Choice 1.1} & \multicolumn{4}{|c|}{ Choice 1.2} \\
\hline \multirow{5}{*}{ Lotteries } & \multicolumn{2}{|c|}{$\mathrm{A}$} & \multicolumn{2}{|c|}{$\mathrm{B}$} & \multicolumn{2}{|c|}{$\mathrm{C}$} & \multicolumn{2}{|c|}{$\mathrm{D}$} \\
\hline & $p$ & $m$ & $p$ & $m$ & $p$ & $m$ & $p$ & $m$ \\
\hline & $100 \%$ & 2400 & $33 \%$ & 2500 & $33 \%$ & 2500 & $34 \%$ & 2400 \\
\hline & & & $66 \%$ & 2400 & $67 \%$ & 0 & $66 \%$ & 0 \\
\hline & & & $1 \%$ & 0 & & & & \\
\hline Expected utility ${ }^{3}$ & \multicolumn{2}{|c|}{943.16} & \multicolumn{2}{|c|}{945.11} & \multicolumn{2}{|c|}{322.63} & \multicolumn{2}{|c|}{320.67} \\
\hline Cumulative prospect & \multicolumn{2}{|c|}{943.16} & \multicolumn{2}{|c|}{871.30} & \multicolumn{2}{|c|}{326.75} & \multicolumn{2}{|c|}{320.12} \\
\hline Results $(N=72)$ & \multicolumn{2}{|c|}{$82 \%$} & \multicolumn{2}{|c|}{$18 \%$} & \multicolumn{2}{|c|}{$83 \%$} & \multicolumn{2}{|c|}{$17 \%$} \\
\hline$p$-Value ${ }^{4}$ & \multicolumn{4}{|c|}{0.00000} & \multicolumn{4}{|c|}{0.00000} \\
\hline
\end{tabular}

Let us collate $\mathrm{K} \& \mathrm{~T}$ experiment with Experiment 1. In the former one, Allais' paradox gained dedicated support. Moreover, those who elected the pair of options AC were $61 \%$ of all participants. This observation as well as the results of other experiments

\footnotetext{
${ }^{3}$ Expected values and cumulative prospects in Tables 2 and 3 were calculated using the utility and weighting functions derived by Tversky and Kahneman in their article introducing the cumulative prospect theory [33]. Calibration came from the same source. Expected utility for positive outcomes were calculated with the formula

$$
E(v(m))=p_{1} m_{1}^{0.88}+p_{2} m_{2}^{0.88}+\ldots+p_{t} m_{t}^{0.88}, p_{1}+p_{2}+\ldots+p_{t}=1
$$

Cumulative prospects calculation is more complicated. First, we order outcomes within the lottery from the highest to the lowest. Then, for every outcome $m_{i}$ we calculate the cumulative probability of winning $m_{i}$ or more (marked $r_{i}$ ), and the cumulative probability of winning more than $m_{i}$ (marked $q_{i}$ ). Subsequently, we are ready to calculate the decision variable according to Tversky and Kahneman [33]
}

$$
w(p)=\frac{r^{0.61}}{\left(r^{0.61}+(1-r)^{0.61}\right)^{1 / 0.61}}-\frac{q^{0.61}}{\left(q^{0.61}+(1-q)^{0.61}\right)^{1 / 0.61}}
$$

Eventually, we are ready to calculate cumulative prospect

$$
C P(v(m))=w\left(p_{1}\right) m_{1}^{0.88}+w\left(p_{2}\right) m_{2}^{0.88}+\ldots+w\left(p_{t}\right) m_{t}^{0.88}, p_{1}+p_{2}+\ldots+p_{t}=1
$$

${ }^{4}$ All $p$-values refer to $\chi^{2}$ tests. 
induced Kahneman and Tversky to define the certainty effect, which led people to overestimate options with probability regarded as $100 \%$ [15].

Table 3. Experiment 1

\begin{tabular}{|l|c|c|c|c|c|c|c|c|}
\hline Choices & \multicolumn{3}{|c|}{ Choice 1.1} & \multicolumn{3}{c|}{ Choice 1.2} \\
\hline \multirow{3}{*}{ Lotteries } & \multicolumn{2}{|c|}{$\mathrm{A}$} & \multicolumn{2}{|c|}{$\mathrm{B}$} & \multicolumn{2}{c|}{$\mathrm{C}$} & \multicolumn{2}{c|}{$\mathrm{D}$} \\
\cline { 2 - 9 } & $p$ & $m$ & $p$ & $m$ & $p$ & $m$ & $p$ & $m$ \\
\cline { 2 - 8 } & $100 \%$ & 100 & $10 \%$ & 500 & $11 \%$ & 100 & $10 \%$ & 500 \\
\cline { 2 - 8 } & & & $89 \%$ & 100 & $89 \%$ & 0 & $90 \%$ & 0 \\
\cline { 2 - 8 } & & & $1 \%$ & 0 & & & & \\
\hline Expected utility & 57.54 & 74.93 & 6.33 & 23.72 \\
\hline Cumulative prospect & 57.54 & 85.92 & 11.23 & 44.19 \\
\hline \multirow{2}{*}{ Results $(N=90)$} & 33 & 57 & 5 & 85 \\
\cline { 2 - 8 } & $37 \%$ & $63 \%$ & $6 \%$ & $94 \%$ \\
\hline$p$-Value & \multicolumn{3}{|c|}{0.0114} & \multicolumn{5}{c|}{0.0000} \\
\hline
\end{tabular}

As in the $\mathrm{K} \& \mathrm{~T}$ experiment, in choice 1.2 , lottery $\mathrm{D}$ was significantly preferred over lottery $\mathrm{C}$, but choice 1.2 brought the results supporting the EU hypothesis. As predicted by the EUT, lottery B was significantly more often chosen than lottery A, and D more often than C. The support weakens when one looks at the intersected choices (Table 4).

Table 4. Experiment 1 - intersected choices

\begin{tabular}{|l|c|c|c|c|}
\hline Pairs & AC & AD & BC & BD \\
\hline \multirow{2}{*}{ Results $(N=90))$} & 2 & 31 & 3 & 54 \\
\cline { 2 - 5 } & $2.2 \%$ & $34.4 \%$ & $3.3 \%$ & $60.1 \%$ \\
\hline
\end{tabular}

The pair of choices representing Allais' paradox was the second one as far as quantity is concerned. Except for the $\mathrm{K} \& \mathrm{~T}$ experiment (61\% pairs of choices supporting Allais' paradox) [15], other important experiments supported AD (Table 3.) in the range between $27 \%$ and $42 \%$ [22]. The results of Experiment 1 fit this interval. Furthermore, in Experiment 1, those who chose $\mathrm{D}$ in the second one significantly dominate among those who elected A in choice $2.1(p=0.0000)$.

Weaker support from testing the original set of lotteries may result from diminishing the difference between rewards and increasing the probability of winning the smaller one in $\mathrm{K} \& \mathrm{~T}$ experiment. Both values of the expected utility function and the cumulative prospect function for Allais lotteries indicate pair BD (Table 2), which significantly dominated pair $\mathrm{AD}$ in Experiment $1(p=0.0126)$. However, in $\mathrm{K} \& \mathrm{~T}$ 's experiment, pair $\mathrm{AC}$ indicated by the values of cumulative prospects, and supporting the violation of independence axiom, contradicts the expected utility theory $E U(\mathrm{~B})>E U(\mathrm{~A})$ (Table 3). For subjects, the Allais paradox was more appealing within the set of lotteries from $\mathrm{K} \&$ T's experiment. Perhaps, Experiment 1 proves why Kahneman and Tversky did not test Allais' original set of lotteries. 


\section{Experiment 2}

The second experiment is a repetition of Loomes, Starmer and Sudgen's study [18]. It was inspired by the preceding articles that tried to explain the EUT transitivity axiom violations $[14,17,29]$. These authors independently and in different ways argued that preference reversals revealed by the experiments did not violate the transitivity axiom but others, which may very often result from the shortcomings of experimental design. Loomes, Starmer and Sudgen (LSS) performed an experiment that was supposed to test the EUT in search of systematic violation of the transitivity axiom. The hypothesis was that the systematic violation of the transitivity axiom is explained by regret theory [19].

The LSS experiment was designed to avoid allegations that the procedure may corrupt the results $[18$, p. 432-436]. The authors projected ten triplets of lotteries. In every triplet, the value was diminishing along with the growth of probability. Within every triplet, lotteries were associated in three pairs constituting decision alternatives. The choices were presented to participants in various orders. In Experiment 2, the test of triplet number 1 (Table 5) was repeated.

Table 5. The LSS experiment. First triplet of lotteries and choices

\begin{tabular}{|l|c|c|c|c|c|c|}
\hline \multirow{4}{*}{ Lotteries } & \multicolumn{2}{|c|}{$\mathrm{A}$} & \multicolumn{2}{c|}{$\mathrm{B}$} & \multicolumn{2}{c|}{$\mathrm{C}$} \\
\cline { 2 - 7 } & $p$ & $m$ & $p$ & $m$ & $p$ & $m$ \\
\cline { 2 - 7 } & $30 \%$ & 18 & $60 \%$ & 8 & $100 \%$ & 4 \\
\cline { 2 - 7 } & $70 \%$ & 0 & $40 \%$ & 0 & $0 \%$ & 0 \\
\hline \multirow{2}{*}{ Choices } & \multicolumn{2}{|c|}{2.1} & \multicolumn{2}{c|}{2.2} & \multicolumn{2}{c|}{2.3} \\
\cline { 2 - 7 } & $\mathrm{A}$ & $\mathrm{B}$ & $\mathrm{B}$ & $\mathrm{C}$ & $\mathrm{A}$ & $\mathrm{C}$ \\
\hline
\end{tabular}

Source: [18].

The possible sequences of choices reflect particular orders of preferences. The first six out of eight are consistent with possible orders that meet the transitivity axiom of the EUT. They are also consistent with regret theory. The last two are closed cycles of preferences inconsistent with the transitivity axiom. The BCA order of choices is predicted by regret theory, while the unpredicted one only reverses the preferences. The hypothesis was that the choice between number 7 and 8 is not indifferent to decisionmakers. Otherwise, the transitivity axiom would hold because choices $\mathrm{ABC}$ and BCA would distribute randomly (Table 6).

In both experiments, two choices $\mathrm{ABA}$ (a consequently risky order of preferences) and $\mathrm{BCC}$ (consequently prudent) took almost the same share of the total amount, consecutively $48 \%$ and $47 \%$. The difference is the statistically significant dominance of $\mathrm{BCC}$ over ABA in the LSS experiment $(p=0.0000)$. In Experiment 2 , respondents were more risk-seeking. More important, however, was the distribution of choices $\mathrm{ABC}$ and BCA. In the LSS experiment, the predicted cycle BCA was elected eight times more 
frequently ( $p=0.00097)$. Overall, 98 of the 200 students chose the predicted cycle, while only 19 went in an unpredicted way $\left(p<10^{-13}\right)$ [18, p. 437]. One can thus reject the hypothesis of indifference towards these two orders (numbers 7 and 8). In Experiment 2, the same dominance was also present, but it was significant only at the level of $\alpha=0.1$ $(p=0.0588)$. The violation of the transitivity axiom is systematic and can be explained by regret theory. Motivated by regret associated with not winning the highest reward of 18 , the respondents reversed their preferences. However, the LSS experiment was performed twelve years after the publication of Kahneman and Tversky's article, it gave a significant testimony to the EUT violations. Experiment 2 confirmed its results.

Table 6. The LSS experiment and Experiment 2. Comparison of results

\begin{tabular}{|c|c|c|c|c|c|c|}
\hline No. & EU orders of preferences & Consistent choices & \multicolumn{2}{|c|}{ LSS experiment } & \multicolumn{2}{c|}{ Experiment 2 } \\
\hline 1 & $\mathrm{~A}>\mathrm{B}>\mathrm{C}$ & $\mathrm{ABA}$ & 6 & $6 \%$ & 24 & $27 \%$ \\
\hline 2 & $\mathrm{~A}>\mathrm{C}>\mathrm{B}$ & $\mathrm{ACA}$ & 5 & $5 \%$ & 7 & $8 \%$ \\
\hline 3 & $\mathrm{C}>\mathrm{A}>\mathrm{B}$ & $\mathrm{ACC}$ & 4 & $4 \%$ & 11 & $12 \%$ \\
\hline 4 & $\mathrm{C}>\mathrm{B}>\mathrm{A}$ & $\mathrm{BCC}$ & 42 & $42 \%$ & 18 & $20 \%$ \\
\hline 5 & $\mathrm{~B}>\mathrm{C}>\mathrm{A}$ & $\mathrm{BBC}$ & 9 & $9 \%$ & 13 & $14 \%$ \\
\hline 6 & $\mathrm{~B}>\mathrm{A}>\mathrm{C}$ & $\mathrm{BBA}$ & 16 & $16 \%$ & 10 & $11 \%$ \\
\hline 7 & unpredicted cycle & $\mathrm{ABC}$ & 2 & $2 \%$ & 1 & $1 \%$ \\
\hline 8 & predicted cycle & $\mathrm{BCA}$ & 16 & $16 \%$ & 6 & $7 \%$ \\
\hline \multicolumn{2}{|l|}{ Total } & 100 & $100 \%$ & 90 & $100 \%$ \\
\hline
\end{tabular}

Source: [18].

\section{Experiment 3}

The third experiment is the repetition of one of the tests presented in Kahneman and Tversky's article. It constitutes a comparison of choices from problems 7 and 8 [15]. It was designed to test another reversal of preferences violating the substitution axiom. According to this axiom, if $(0<p, q, r<1)$ :

$$
p v(m) \succ q v\left(m^{\prime}\right), \text { then } r p v(m) \succ r q v\left(m^{\prime}\right)
$$

The idea was to face subjects with two choices. One was a pair of lotteries with significant probabilities and equal expected values, while the alternative is the first pair of lotteries multiplied by the same, very low probability. Obviously, the expected values in the second pair are also equal.

Preference is indifferent towards mutual multiplication of both lotteries by the same probability. Hence, if the subject prefers B to A, he or she should also prefer D over C. Results of both experiments violate the substitution axiom. Lottery B was significantly chosen more often than A. The same groups of subjects elected lottery $\mathrm{C}$ significantly 
more frequently than lottery D. Reversal of preferences appeared in both experiments with statistical significance. The same results were achieved by MacCrimmon and Larsson [22]. In Experiment 3, there is more evidence for violation of the substitution axiom. Let us focus on individual choices of subjects in both pairs 3.1 and 3.2 (Table 7).

Table 7. K \& T experiment (problems 7 and 8) and Experiment 3

\begin{tabular}{|c|c|c|c|c|c|c|c|c|}
\hline Choices & \multicolumn{4}{|c|}{ Choice 3.1} & \multicolumn{4}{|c|}{ Choice 3.2} \\
\hline \multirow{4}{*}{ Lotteries } & \multicolumn{2}{|c|}{$\mathrm{A}$} & \multicolumn{2}{|c|}{$\mathrm{B}$} & \multicolumn{2}{|c|}{$\mathrm{C}$} & \multicolumn{2}{|c|}{$\mathrm{D}$} \\
\hline & $p$ & $m$ & $p$ & $m$ & $p$ & $m$ & $p$ & $m$ \\
\hline & $45 \%$ & 6000 & $90 \%$ & 3000 & $0.1 \%$ & 6000 & $0.2 \%$ & 3000 \\
\hline & $55 \%$ & 0 & $10 \%$ & 0 & $99.9 \%$ & 0 & $99.8 \%$ & 0 \\
\hline \multirow{2}{*}{ K \& T's results $(N=66)$} & \multicolumn{2}{|c|}{9} & \multicolumn{2}{|c|}{57} & \multicolumn{2}{|c|}{48} & \multicolumn{2}{|c|}{18} \\
\hline & & $1 \%$ & & $\%$ & 73 & & 27 & \\
\hline$p$-Value & \multicolumn{4}{|c|}{0.00000} & \multicolumn{4}{|c|}{0.00022} \\
\hline \multirow{2}{*}{ Results of Experiment $3(N=90)$} & \multicolumn{2}{|c|}{19} & \multicolumn{2}{|c|}{71} & \multicolumn{2}{|c|}{60} & \multicolumn{2}{|c|}{30} \\
\hline & & $\%$ & \multicolumn{2}{|c|}{$79 \%$} & 67 & & \multicolumn{2}{|c|}{$33 \%$} \\
\hline$p$-Value & \multicolumn{4}{|c|}{0.00000} & \multicolumn{4}{|c|}{0.00157} \\
\hline
\end{tabular}

Source: [15] and author's study.

Table 8. Subjects' pairs of choices in Experiment 3

\begin{tabular}{|c|c|c|c|c|c|c|c|c|}
\hline Choices & \multicolumn{4}{|c|}{ Choice 3.1} & \multicolumn{4}{|c|}{ Choice 3.2} \\
\hline \multirow{4}{*}{ Lotteries } & \multicolumn{2}{|c|}{$\mathrm{A}$} & \multicolumn{2}{|c|}{$\mathrm{B}$} & \multicolumn{2}{|c|}{$\mathrm{C}$} & \multicolumn{2}{|c|}{$\mathrm{D}$} \\
\hline & $p$ & $m$ & $p$ & $m$ & $p$ & $m$ & $p$ & $m$ \\
\hline & $45 \%$ & 6000 & $90 \%$ & 3000 & $0.1 \%$ & 6000 & $0.2 \%$ & 3000 \\
\hline & $55 \%$ & 0 & $10 \%$ & 0 & $99.9 \%$ & 0 & $99.8 \%$ & 0 \\
\hline \multirow{3}{*}{ Results of Experiment $3(N=90)$} & \multicolumn{2}{|c|}{$\mathrm{AC}$} & \multicolumn{2}{|c|}{$\mathrm{AD}$} & \multicolumn{2}{|c|}{$\mathrm{BC}$} & \multicolumn{2}{|c|}{$\mathrm{BD}$} \\
\hline & \multicolumn{2}{|c|}{13} & \multicolumn{2}{|c|}{6} & \multicolumn{2}{|c|}{47} & \multicolumn{2}{|c|}{24} \\
\hline & \multicolumn{2}{|c|}{$68 \%$} & \multicolumn{2}{|c|}{$32 \%$} & \multicolumn{2}{|c|}{$66 \%$} & \multicolumn{2}{|c|}{$34 \%$} \\
\hline$p$-Value & \multicolumn{4}{|c|}{0.10829} & \multicolumn{4}{|c|}{0.00634} \\
\hline
\end{tabular}

Source: [15] and author's study.

The subjects who elected $\mathrm{B}$ in the first alternative chose $\mathrm{C}$ significantly more often than $\mathrm{D}$ in the second one $(p=0.00634)$ (Table 8$)$. At the same time, among subjects who did not behave according to the expected utility theory, pair BC strongly dominated pair $\operatorname{AD}(p=0.00000)$. There is a systematic violation of the substitution axiom. Kahneman and Tversky explained it by claiming that subjects faced with the alternative of lotteries that are "possible but not probable" choose the one with a higher reward [15]. This property was incorporated in prospect theory. 


\section{Experiment 4}

The fourth experiment is the replication of the Kahneman and Tversky's test on loss aversion [15]. This phenomenon is the one with the strongest empirical evidence. Initially, Markovitz in his experiment noted that people generally avoided symmetric bets. This implied the utility curve falling faster to the left of the origin than rising to the right of the origin (i.e., $v(m)<|v(-m)|$ for $m>0$ ) [24]. Later on, Williams confirmed the existence of loss aversion in the experiment on people's attitude towards insurance [34]. Kahneman and Tversky [33] introduced a coefficient $\lambda$ defined as

$$
\lambda=-\frac{-v(-1)}{v(1)}
$$

The coefficient $\lambda$ shows how losses of the same absolute value are more strongly perceived in comparison to gains. The first estimate by Kahneman and Tversky was $\lambda=2.25$. Contemporary research no longer tests the existence of loss aversion, but develops the measurement of it (Table 9).

Table 9. Loss aversion estimates for monetary values

\begin{tabular}{|c|c|c|}
\hline Authors & Definition & Estimated $\lambda$ \\
\hline Kahneman and Tversky [33] & $\lambda=\frac{-v(-1)}{v(1)}$ & 2.25 \\
\hline Schmidt and Traub [28] & \multirow{2}{*}{$\lambda=\frac{v^{\prime}(-m)}{v^{\prime}(m)}$} & 1.43 \\
\hline Pennings and Smidts [26] & & 1.80 \\
\hline Abdellaoui et al. [1] & $\lambda=\frac{v_{+}^{\prime}(0)}{v_{-}^{\prime}(0)}$ & 1.69 \\
\hline Booji and van de Kuilen [8] & \multirow{2}{*}{$\lambda=\frac{v^{\prime}(-m)}{v^{\prime}(m)}$} & 1.87 \\
\hline Gurevich et al. [13] & & 1.12 \\
\hline Booji et al. [9] & $\lambda=\frac{-v(-1)}{v(1)}$ & 1.60 \\
\hline von Gaudecker et al. [35] & $\lambda=\frac{v^{\prime}(-m)}{v^{\prime}(m)}$ & 2.38 \\
\hline Abdellaoui et al. [2] & $\lambda=\frac{-v(-1)}{v(1)}$ & 3.50 \\
\hline
\end{tabular}

All the estimates in Table 8 are higher than 1 . The undisputed loss aversion phenomenon affects people's choices under risk. Kahneman and Tversky named it the reflection effect and devoted a full section to present four pairs of experiments testing it [15]. Choices within problems 3, 4, 7 and 8 made for positive values were confronted 
with outcomes for the mirror images from the negative side of the numerical axis. All four comparisons revealed a reversal of preferences as far as negative values were concerned, three of them statistically significant.

Experiment 4 was performed on lotteries from K \& T's problems 3 and $3^{\prime}$. The first was the one that tested the preference reversal implied by the certainty effect. The second pair of lotteries is its mirror image.

Participants of both experiments reversed their preferences toward risk when faced with the choice between sure lower loss, and the higher loss with the chance of avoidance. Both in K \& T's study and the present one, the results were statistically significant. The reversal of attitude towards risk can only be explained by loss aversion. People are willing to risk a higher loss if there is a higher probability of avoiding it at all. In particular, the results of both experiments showed that certainty increases the intensiveness of loss aversion as well as the desirability of gains (Table 10).

Table 10. K \& T experiment (problems 3 and $3^{\prime}$ ) and Experiment 4

\begin{tabular}{|c|c|c|c|c|c|c|c|c|}
\hline Choices & \multicolumn{4}{|c|}{ Choice 4.1} & \multicolumn{4}{|c|}{ Choice 4.2} \\
\hline \multirow{4}{*}{ Lotteries } & \multicolumn{2}{|c|}{$\mathrm{A}$} & \multicolumn{2}{|c|}{$\mathrm{B}$} & \multicolumn{2}{|c|}{$\mathrm{C}$} & \multicolumn{2}{|c|}{$\mathrm{D}$} \\
\hline & $p$ & $m$ & $p$ & $m$ & $p$ & $m$ & $p$ & $m$ \\
\hline & $100 \%$ & 3000 & $80 \%$ & 4000 & $100 \%$ & -3000 & $80 \%$ & -4000 \\
\hline & $0 \%$ & 0 & $20 \%$ & 0 & $0 \%$ & 0 & $20 \%$ & 0 \\
\hline \multirow{2}{*}{$\mathrm{K} \& \mathrm{~T}$ 's results $(N=95)$} & \multicolumn{2}{|c|}{76} & \multicolumn{2}{|c|}{19} & \multicolumn{2}{|c|}{8} & \multicolumn{2}{|c|}{87} \\
\hline & 80 & & & $\%$ & & $\%$ & & $2 \%$ \\
\hline$p$-Value & \multicolumn{4}{|c|}{0.00000} & \multicolumn{4}{|c|}{0.00000} \\
\hline \multirow{2}{*}{ Results of experiment $4(N=90)$} & \multirow{2}{*}{\multicolumn{2}{|c|}{$\begin{array}{c}56 \\
62 \%\end{array}$}} & \multicolumn{2}{|c|}{34} & \multicolumn{2}{|c|}{28} & \multicolumn{2}{|c|}{62} \\
\hline & & & \multicolumn{2}{|c|}{$38 \%$} & & $1 \%$ & \multicolumn{2}{|c|}{$69 \%$} \\
\hline$p$-Value & \multicolumn{4}{|c|}{0.02039} & \multicolumn{4}{|c|}{0.00034} \\
\hline
\end{tabular}

Source: [15] and author's study.

The results of prior experiments and their study inspired Kahneman and Tversky to design the utility function of the prospect, convex for losses, and concave for gains [15]. Later, in the cumulative prospect, the value function for losses was multiplied by a coefficient $\lambda$ higher than one [33].

\section{Experiment 5}

The fifth experiment tackles the issue of the reference point. The EUT measures the utility of the current state of wealth. Kahneman and Tversky's experiment showed that decision-makers tend to evaluate the changes of wealth regarding a reference point, which is their wealth before making a choice [15]. They faced two separate groups of subjects with the choices presented in Table 11 . 
As far as the final states of wealth are concerned, lotteries A and C are the same, give 2000 with $p=0.5$ and 1000 with $p=0.5$. Options $\mathrm{B}$ and $\mathrm{D}$ guarantee the decision-maker 1500. Regardless of the initial states of wealth, the subject should be indifferent between alternatives $\mathrm{A}$ and $\mathrm{C}$, and between alternatives $\mathrm{B}$ and $\mathrm{D}$, therefore both problems are identical under EUT. Problem 11 was solved in favour of a sure offer of 500, but in Problem 12, participants preferred to gamble by choosing option C. Both results were statistically significant. The reference point matters. Kahneman and Tversky concluded: The apparent neglect of a bonus that was common to both options in Problems 11 and 12 implies that the carriers of value or utility are changes of wealth, rather than final asset positions that include current wealth. This conclusion is the cornerstone of an alternative theory of risky choice [15]. There is further vast evidence supporting the reference point concept, either from experimental or from field studies [10].

Table 11. K \& T experiment (Problems 11 and 12)

\begin{tabular}{|c|c|c|c|c|c|c|c|c|}
\hline Choices & \multicolumn{4}{|c|}{ Problem 11} & \multicolumn{4}{|c|}{ Problem 12} \\
\hline Initial condition & \multicolumn{4}{|c|}{$\begin{array}{l}\text { In addition to whatever you own, } \\
\text { you have been given } 1000 \text {. You are } \\
\text { now asked to choose between: }\end{array}$} & \multicolumn{4}{|c|}{$\begin{array}{l}\text { In addition to whatever you own, } \\
\text { you have been given } 2000 \text {. You are } \\
\text { now asked to choose between: }\end{array}$} \\
\hline \multirow{4}{*}{ Lotteries } & \multicolumn{2}{|c|}{ A } & \multicolumn{2}{|c|}{$\mathrm{B}$} & \multicolumn{2}{|c|}{$\mathrm{C}$} & \multicolumn{2}{|c|}{$\mathrm{D}$} \\
\hline & $p$ & $v$ & $p$ & $v$ & $p$ & $v$ & $p$ & $v$ \\
\hline & $50 \%$ & 1000 & $100 \%$ & 500 & $50 \%$ & -1000 & $100 \%$ & -500 \\
\hline & $50 \%$ & 0 & $0 \%$ & 0 & $50 \%$ & 0 & $0 \%$ & 0 \\
\hline \multirow{2}{*}{$\begin{array}{l}\text { Results }(N=70 \\
\text { and } N=68)\end{array}$} & \multicolumn{2}{|c|}{11} & \multicolumn{2}{|c|}{59} & \multicolumn{2}{|c|}{47} & \multicolumn{2}{|c|}{21} \\
\hline & \multicolumn{2}{|c|}{$16 \%$} & \multicolumn{2}{|c|}{$84 \%$} & \multicolumn{2}{|c|}{$69 \%$} & \multicolumn{2}{|c|}{$31 \%$} \\
\hline$p$-Value & \multicolumn{4}{|c|}{0.00000} & \multicolumn{4}{|c|}{0.01907} \\
\hline
\end{tabular}

Source: [15] and author's study.

The focus on the changes of wealth in prospect theory is undisputed; however, there are some doubts towards the experiments using Problems 11 and 12 (Table 11). The first, possibly the dominant choice would be $\mathrm{BC}$ regardless of the initial states of wealth. Choosing B in Problem 11 was strongly motivated by the certainty effect. In Problem 12 , preference towards lottery $\mathrm{C}$ was implied by loss aversion. These doubts inspired the present author to test choices under risk with a reference point, but on lotteries with other effects absent. Kahneman proposed the set of choices himself in his book [16].

Formulation of the alternatives resulted in two pairs of identical choices, regardless of the initial conditions. Choosing between the final states of wealth hides the distinction between gains and losses. Subjects are to calculate changes of wealth themselves, contrary to Problems 11 and 12 where these changes were presented directly and states of wealth at the end were hidden behind the calculation. Taking a different set of choices was not the only difference: both decisions were made by the same sample of subjects. The instructions for choices 5.1 and 5.2 were presented on the same page. The choices 
were made not only by the same subjects, but they could see both at the same time (Table 12).

Table 12. Experiment 5

\begin{tabular}{|c|c|c|c|c|c|c|c|c|}
\hline Choices & \multicolumn{4}{|c|}{ Choice 5.1} & \multicolumn{4}{|c|}{ Choice 5.2} \\
\hline Initial condition & \multicolumn{4}{|c|}{$\begin{array}{l}\text { Your current wealth is } 1 \text { million. } \\
\text { You are faced with the options } \\
\text { that will leave you with }\end{array}$} & \multicolumn{4}{|c|}{$\begin{array}{l}\text { Your current wealth is } 4 \text { million. } \\
\text { You are faced with the options } \\
\text { that will leave you with }\end{array}$} \\
\hline \multirow{4}{*}{ Lotteries } & \multicolumn{2}{|r|}{ A } & \multicolumn{2}{|r|}{ B } & \multicolumn{2}{|r|}{$\mathrm{C}$} & \multicolumn{2}{|c|}{$\mathrm{D}$} \\
\hline & $p$ & $v[\mathrm{mln}]$ & $p$ & $v[\mathrm{mln}]$ & $p$ & $v[\mathrm{mln}]$ & $p$ & $v[\mathrm{mln}]$ \\
\hline & $50 \%$ & 1 & $100 \%$ & 2 & $50 \%$ & 1 & $100 \%$ & 2 \\
\hline & $50 \%$ & 4 & $0 \%$ & 0 & $50 \%$ & 4 & $0 \%$ & 0 \\
\hline \multirow{2}{*}{ Results $(N=90)$} & \multicolumn{2}{|r|}{57} & \multicolumn{2}{|c|}{33} & \multicolumn{2}{|c|}{56} & \multicolumn{2}{|c|}{34} \\
\hline & \multicolumn{2}{|c|}{$63 \%$} & \multicolumn{2}{|c|}{$37 \%$} & & $2 \%$ & \multicolumn{2}{|c|}{$38 \%$} \\
\hline$p$-Value & \multicolumn{4}{|c|}{0.01141} & \multicolumn{4}{|c|}{0.02039} \\
\hline
\end{tabular}

Source: [16] and author's study.

The results of Experiment 5 support the EUT: participants prefer risky options in both decisions with statistical significance. Does it question the existence of the reference point within the process of decision-making under risk? Surely not, but it should focus the researcher's attention on the formulation of the problem. The first experiments presented options hiding the final states of wealth, while the second obscured the changes of wealth. The first one stressed the distinction between gains and losses, and the second left it to decision-makers calculation. The first one tested alternatives in isolation, while the second presented them to the same subjects. This might bias the participants of Experiment 5 in favour of comparing both pairs and focusing on the lotteries, without considering the initial states of wealth.

All these differences are linked to the framing effect, which was also diagnosed by Tversky and Kahneman [32]. Hiding the final states of wealth in the first experiment and changes of wealth in the second behind calculations may corrupt choices, according to Kahneman's concept of thinking fast and slow [16]. Perhaps the subjects made their decisions using only System 1 (which) operates automatically and quickly, with little or no effort and no sense of voluntary control [16, p. 22]. Revealing hidden information demanded System 2, which allocates attention to effortful mental activities, including complex computations. The operations of System 2 are often associated with the subjective experience of agency, choice, and concentration [16 p. 22].

The results of Experiment 5 did not undermine the presence of a reference point within decision-making under risk, but it indicated the necessity of designing experiments to be free from unwanted biases. For example, one may project two similar pairs of lotteries, each with a different initial state of wealth. 


\section{Summary}

Shortly after the announcement of the expected utility theory in its axiomatic version, evidence from experimental results revealing incompatibilities between the EUT predictions and human behaviour under risk started to grow. On the one hand, it undermined the positive capacity of the theory. On the other hand, growing evidence of people's real choices revealed regularities that contradicted the EUT axioms. Researchers working on a new concept explaining people's choices under risk had therefore knowledge based on empirical facts that could not be ignored by any new theory. The most eminent examples are certainty effect, loss aversion, and reference point significance.

Prospect theory was invented to explain all known aspects of real decisions under risk. Therefore, an appropriate summary accomplishing the goal of the article is the test of the predictive capacity of prospective theory. The results of all five experiments were compared with the cumulative prospect values of all the lotteries that appeared in them.

Table 13. Predictive power of the CPT model calibrated by Tversky and Kahneman

\begin{tabular}{|l|l|c|c|c|c|}
\hline \multicolumn{2}{|c|}{ Lotteries } & $\mathrm{A}$ & $\mathrm{B}$ & $\mathrm{C}$ & $\mathrm{D}$ \\
\hline \multirow{2}{*}{ Experiment 1 } & results & $37 \%$ & $63 \%$ & $6 \%$ & $94 \%$ \\
\cline { 2 - 6 } & cumulative prospects & 57.54 & 85.92 & 11.23 & 44.19 \\
\hline \multirow{2}{*}{ Experiment 2 } & results & $\mathrm{A}>\mathrm{B}, \mathrm{C}>\mathrm{B}$, and $\mathrm{A}>\mathrm{C}$ with $8 \%$ frequency \\
\cline { 2 - 6 } & cumulative prospects & 4.05 & 2.95 & 3.39 & \\
\hline \multirow{2}{*}{ Experiment 3 } & results & $21 \%$ & $79 \%$ & $67 \%$ & $33 \%$ \\
\cline { 2 - 6 } & cumulative prospects & 834.87 & 816.91 & 30.53 & 25.03 \\
\hline \multirow{2}{*}{ Experiment 4 } & results & $62 \%$ & $38 \%$ & $31 \%$ & $69 \%$ \\
\cline { 2 - 6 } & cumulative prospects & 1147.8 & 898.1 & -2582.6 & -2020.7 \\
\hline \multirow{2}{*}{ Experiment 5 } & results & $63 \%$ & $37 \%$ & $62 \%$ & $38 \%$ \\
\cline { 2 - 6 } & cumulative prospects & 1.11 & 1.00 & -3.43 & -4.14 \\
\hline
\end{tabular}

The values of the cumulative prospects were calculated for the set of parameters calibrated by Tversky and Kahneman [33]. One should be cautious about concluding from the study presented in Table 13. Firstly, it is only a single set of experiments. Secondly, only one set of value and probability weight functions was applied. Nevertheless, the outcome is worth consideration.

All the differences within the choices in experiments 1,3-5 were statistically significant. Only the results of Experiment 2 and the first choice in Experiment 3 were not consistent with the predictions of cumulative prospect theory (bold figures). The results of Experiment 2, compatible with the outcome of the original study by Loomes, Starmer and Sudgen, introduced regret theory that explained the violation of the EUT transitivity axiom. It is worth investigating if it undermines the predictive capacity of prospect theory. The dominance of the predicted reverse in the choice between A and B in Experiment 3 was present also in the original experiment by Kahneman and Tversky [15]. The 
explanation could be the small difference between the cumulative prospect values. For a slightly smaller parameter $\alpha=0.8$ (more risk-averse) the prediction fits the results. All the other seven predictions were compatible with the predictions of cumulative prospect theory. That result supports cumulative prospect theory as a progressive scientific research program.

\section{References}

[1] Abdellaoui M., Bleichrodt H., Paraschiv C., Loss Aversion under Prospect Theory: A Parameter-Free Measurement, Manage. Sci., 2007, 53 (10), 1659-1674.

[2] Abdellaoui M., Kemel E., Eliciting Prospect Theory when Consequences Are Measured in Time Units: Time is Not Money, Manage. Sci., 2014, 60 (7), 1844-1859.

[3] Allais M., The Behavior of Rational Man in the Face of Risk. Critique of the Postulates and Axioms of the American School, Econometrica, 1953, 21 (4), 503-546 (in French).

[4] Allais M., The So-Called Allais Paradox and Rational Decisions under Uncertainty, [In:] M. Allais, O. Hagen (Eds.), Expected Utility and the Allais Paradox, D. Reidel, Dordrecht 1979, 437-683.

[5] Expected Utility and the Allais Paradox, Allais M., O. Hagen (Eds.), D. Reidel, Dordrecht 1979.

[6] Andreoni J., Sprenger C., Certain and Uncertain Utility: The Allais Paradox and Five Decision Theory Phenomena, Researchgate, 2010. https://www.researchgate.net/publication/229053537_Certain_and_Uncertain_Utility_The_Allais_Paradox_and_Five_Decision_Theory_Phenomena

[7] Bernoulli D., Exposition of a New Theory on the Measurement of Risk, Econometrica, 1954, 22 (1), 23-36.

[8] Boolj A.S., VAn De Kuilen G., A Parameter-Free Analysis of the Utility of Money for the General Population under Prospect Theory, J. Econ. Psych., 2009, 30 (4), 651-666.

[9] Boolj A.S., van PraAg B.M.S., van De KuILen G., A Parametric Analysis of Prospect Theory's Functionals for the General Population, Theory and Decision, 2010, 68 (1-2), 115-148.

[10] CAMERER C.F., Prospect theory in the wild: Evidence from the field, [In:] D. Kahneman, A. Tversky (Eds.), Choices, Values, and Frames, Cambridge University Press, Cambridge, UK, 2000, 288-300.

[11] Ding S., Lugovskyy V., Puzzello D., Tucker S., Williams A., Cash versus Extra-Credit Incentives in Experimental Asset Markets, J. Econ. Beh. Org., 2018, 150, 19-27.

[12] Grossman P., Komai M., Incentivizing Experiments: Monetary Rewards versus Extra Credits, St. Cloud State University Economics Faculty Working Papers, 2006, 9, 1-33.

[13] Gurevich G., Kliger D., Levy O., Decision-Making under Uncertainty. A Field Study of Cumulative Prospect Theory, J. Bank. Fin., 2009, 33 (7), 1221-1229.

[14] Holt C.A., Preference Reversals and the Independence Axiom, American Economic Review, 1986, $76(3), 508-515$.

[15] Kahneman D., Tversky A., Prospect Theory. An Analysis of Decision under Risk, Econometrica, 1979, 47 (2), 263-291.

[16] Kahneman D., Thinking, Fast and Slow, Ferrar Straus Giroux, New York 2012, 267.

[17] KARNi E., SAFra Z., Preference Reversal and the Observability of Preferences by Experimental Methods, Econometrica, 1987, 55 (3), 675-685.

[18] LoOmes G., Starmer C., Sugden R., Observing Violations of Transitivity by Experimental Methods, Econometrica, 1991, 59 (2), 425-439.

[19] Loomes G., Sugden R., Regret theory. An alternative theory of rational choice under uncertainty, Econ. J., 1982, 92 (4), 805-824. 
[20] LuCCASSEN A., THOMAS K., Monetary incentives versus class credit: Evidence from a large classroom trust experiment, Econ. Lett., 2014, 123 (2), 232-235.

[21] MacCrimmon K.R., Descriptive and Normative Implications of the Decision-Theory Postulates, [In:] K. Borch, J. Mossin (Eds.), Risk and Uncertainty, MacMillan, London 1968, 3-23.

[22] MacCrimmon K.R., Larsson S., Utility Theory: Axioms versus Paradoxes, [In:] M. Allais, O. Hagen (Eds.), Expected Utility and the Allais Paradox, D. Reidel, Dordrecht 1979, 333-409.

[23] Machina M., Expected Utility. Analysis without the Independence Axiom, Econometrica, 1982, 50 (2), 277-323.

[24] Markowitz H., The Utility of Wealth, J. Polit. Econ., 1952, 60 (2), 151-158.

[25] Moskowitz H., Effects of Problem Representation and Feedback on Rational Behavior in Allais and Morlat-Type Problems, Dec. Sci., 1974, 5 (2), 225-241.

[26] Pennings J.M.E., Smidts A., The Shape of Utility Functions and Organizational Behavior, Manage. Sci., 2003, 49 (9), 1251-1263.

[27] Savage L.J., The Foundations of Statistics, Dover Publications, Inc., New York 1972.

[28] Schmidt U., Traub S., An Experimental Test of Loss Aversion, J. Risk Uncert., 2002, 25 (3), 233-249.

[29] Segal U., Does the Preference Reversal Phenomenon Necessarily Contradict the Independence Axiom?, Am. Econ. Rev., 1988, 78 (1), 233-236.

[30] Slovic P., TVersky A., Who Accepts Savage's Axioms?, Beh. Sci., 1974, 19, 6, 368-378.

[31] Sмith V.L., Economics in the Laboratory, J. Econ. Persp., 1994, 8 (1), 113-131.

[32] TVersky A., Kahneman D., The Framing of Decisions and the Psychology of Choice, Science, 1981, 211 (4481), 453-458.

[33] TVersky A., Kahneman D., Advances in Prospect Theory. Cumulative Representation of Uncertainty, J. Risk Uncert., 1992, 5 (4), 297-323.

[34] Williams A.C., Attitudes toward Speculative Risks as an Indicator of Attitudes toward Pure Risks, J. Risk Insur., 1966, 33 (4), 577-586.

[35] Von Gaudecker H., van Soest A., Wengström E., Heterogeneity in Risky Choice Behavior in a Broad Population, Amer. Econ. Rev., 2011, 101 (2), 664-694.

[36] Von Neumann J., Morgenstern O., Theory of Games and Economic Behavior, Princeton University Press, Princeton, New York 1953. 